\title{
In vitro activity of tigecycline against local clinical isolates of some Enterobacteriaceae
}

\author{
Hadeel A. Eldeeb ${ }^{1, *}$, Fathy M. Serry ${ }^{1}$, Naglaa F. Ghoname ${ }^{2}$, Hisham A. Abbas ${ }^{1}$ \\ ${ }^{1}$ Zagazig University, faculty of pharmacy, department of microbiology and immunology \\ ${ }^{2}$ Tanta University, faculty of medicine, department of microbiology and immunology \\ *Corresponding author: Tel. No.00201003350529, Email: had88@yahoo.com \\ Received:4Mar 2020 /Accepted: 2 May 2020 /Published online : 20 Jul 2020
}

\section{ABSTRACT}

Infectious diseases that Enterobacteriaceae cause are spreading on a wide scale. Examples of these infections are gastrointestinal tract infections, meningitis, pneumonia, septicemia, urinary tract infections, and wound infections. Antibiotic resistance among Enterobacteriaceae is a critical problem that makes treatment difficult. Tigecycline is a broad spectrum antibiotic that is effective against multi-drug resistant organisms (MDR) and may be beneficial in the therapy of infections caused by Enterobacteriaceae.

This study aims to evaluate the in vitro activity of tigecycline against clinical isolates of Enterobacteriaceae species and detect the possible resistance mechanisms of them against $\beta$ lactams.

The sensitivity of different isolates to antibiotics was determined by standard disc diffusion method. Phenotypic detection of resistance mechanisms such as extended spectrum $\beta$-lactamase (ESBL), AmpC, ESBL\& AmpC co-producers and metallo $\beta$-lactamase (MBL) $\beta$-lactamases enzymes producer isolates was investigated.

A total of eighty three Enterobacteriaceae clinical isolates were collected. The common bacteria isolated were Escherichia coli and Klebsiella pneumoniae. Multidrug resistance was found in 59.04\% of tested isolates. The isolates were resistant to sulfamethoxazole-trimethoprim, ciprofloxacin, tetracycline and impenem. The highest resistance was found to sulfamethoxazoletrimethoprim followed by ciprofloxacin, tetracycline and imipenem. Phenotypic detection of resistance mechanisms revealed that $69.4 \%$ of clinical isolates were ESBL producers, $12.2 \%$ were AmpC producers, and 8.2\% were ESBL and AmpC co-producers, while $10.2 \%$ were MBL producers. There was no resistance found to tigecycline among all Enterobacteriaceae isolates tested.

This study showed that tigecycline has potent in vitro activity against ESBL, AmpC, combined ESBL and AMPC and MBL $\beta$-lactamases producing Enterobacteriaceae.

Keywords :Enterobacteriaceae, tigecycline, antibiotic resistance.

\section{INTRODUCTION}

The Enterobacteriaceae includes numerous genera of Gram-negative bacteria. E.coli, Salmonella, Shigella, Klebsiella, Enterobacter, Serratia, Yersinia, Proteus are examples of the Enterobacteriaceae (Mandell et al. 2009).

Enterobacteriaceae can be present in water, soil in addition to humans and animal intestinal tracts. They are etiological agents of many human diseases such as gastrointestinal tract infections, urinary tract infections, abscesses, meningitis, pneumonia, and septicemia as well as wound infections (Mandell et al. 2009). Furthermore, they are frequent causes of healthcare-associated infections; E.coli is a common cause of UTIs, while Klebsiella spp. and Enterobacter spp. are commonly involved in pneumonia. Moreover, bloodstream infections, peritonitis, cholangitis, 
and other intra-abdominal infections can be caused by Enterobacteriaceae. Also, Salmonella is responsible for gastroenteritis that may be complicated as invasive infection in some patients (Paterson et al. 2006).

Enterobacteriaceae show multidrug resistance to antibiotics that constitutes a worldwide public health dilemma (Partridge $\boldsymbol{e t}$ al. 2015). The factors that are responsible for the spread of antibiotic resistance include the misuse of antibiotics for prophylaxis and therapy of infections in both humans and animals, in addition to their use to promote growth in agriculture (Caron et al. 2018).

Antibiotic resistance of

Enterobacteriaceae, especially $\beta$-lactams is enhanced by mobilization of genes encoding antibiotic inactivating enzymes. Other underlying mechanisms of antibiotic resistance include outer membrane impermeability and drug efflux, so antibiotic resistance to bacteria such as E. coli and $K$. pneumoniae has significantly increased (Iredell et al. 2016).

The production of extended-spectrum betalactamases (ESBLs) and carbapenemaseproducing Enterobacteriaceae (CRE) are contributing to multidrug-resistance in Enterobacteriaceae (Bassetti et al. 2016). The ability of genera of Enterobacteriaceae to produce beta-lactamases is commonly involved in their resistance to penicillins, cephalosporins, or aztreonam (Thenmozhi et al. 2014).

The spreading antimicrobial resistance among Enterobacteriaceae limits the use of traditional antimicrobial agents and necessitates the production of novel classes of antimicrobials (Fair et al. 2014).

Tigecycline is a semi-synthetic derivative of minocycline and it was the first glycylcycline to be used clinically. Unlike other tetracyclines, tigecycline was found to produce very good results activity against many species of Gram-positive and Gram-negative bacteria, including multidrug-resistant ones (Singh $\boldsymbol{e t}$ al. 2017).

The Food and Drug Administration (FDA) approves the use of tigecycline as the best drug for the therapy of complicated infections of skin and soft tissue and intra-abdominal in addition to community-acquired infections affecting lower respiratory tract (Song et al. 2018).

The study aimed to evaluate the in vitro activity of tigecycline antibiotic against local MDR clinical isolates of some Enterobacteriaceae species.

\section{Material and methods}

\section{Media and chemicals}

MacConkey agar, Mueller Hinton agar and broth, Triple sugar iron agar, Simmons citrate agar, Cystine lactose electrolyte deficient (CLED medium) and antibiotic discs were purchased from Oxoid, Hampshire, UK. Nutrient agar was obtained from Lab $M$ limited, Lancoshine, UK. ESBL and AmpC D68C detection set discs were the products of MASTDISCS ID ${ }^{\mathrm{TM}}$. Urea broth medium and Motility medium were prepared and sterilized according to Atlas (Atlas, 2004). Other chemicals were of pharmaceutical grade.

\section{Bacterial strains}

One hundred and sixty specimens were collected from different sources such as urine, endotracheal tube, pus swab, sputum and wound swab. Sterile labeled containers were used for collection of specimens under complete aseptic precautions and the specimens were transported immediately to the microbiological laboratory for processing.

\section{Isolation and identification of Enterobacteriaceae}

Identification of Enterobacteriaceae was performed using standard microbiological techniques such as Gram staining, colony morphology, growth on MacConkey's agar media, motility, oxidase, citrate utilization, 
Zagazig J. Pharm. Sci. June, 2020

Vol. 29, Issue 1, pp. 9-20

urease, indole, and triple sugar iron tests (Cheesbrough, 2006).

\section{Antimicrobial susceptibility testing}

To test the susceptibility of different isolates to antibiotics, the disc diffusion method was used according to Clinical Laboratory Standards Institute guidelines (CLSI, 2017). Each isolate was grown overnight, and the resulting suspensions were diluted with sterile saline to achieve a turbidity that matches 0.5 McFarland Standard. The prepared suspensions were used within 15 minutes. A sterile cotton swab was dipped into each inoculum and the excess liquid was removed by rotating the swab and pressed it firmly on the inner tube wall. The swab was streaked to spread the bacteria on the surface of the MHA plate. Antibiotics discs included amoxicillin-clavulanic acid (AMC, 30 $\mu \mathrm{g}$ ), ceftazidime (CAZ, 30 $\mu \mathrm{g}$ ) cefepime (FEP, 30 $\mu$ ), cefotaxime (CTX, $30 \mu \mathrm{g})$, ceftriaxone $(\mathrm{CRO}, 30 \mu \mathrm{g})$, cefoxitin

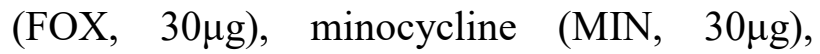
ciprofloxacin (CIP, 5 $\mu \mathrm{g})$, gentamycin $(\mathrm{CN}$, $10 \mu \mathrm{g})$, imipenem (IPM, $10 \mu \mathrm{g})$, tetracycline (TE, $\quad 30 \mu \mathrm{g})$, and sulfamethoxazoletrimethoprim (SXT, 25 $\mu \mathrm{g}), \quad$ ampicillin-

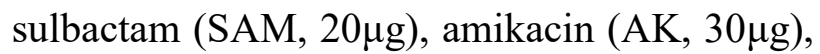
aztreonam (ATM, 30 $\mu$ ), tigecycline (TGC, $15 \mu \mathrm{g})$. After incubation for 24 hours at $37^{\circ} \mathrm{C}$, the inhibition zone diameters were measured and the results were interpreted using CLSI guidelines (CLSI, 2017) for all antibiotics except for tigecycline for which (EUCAST, 2016) breakpoints were used for interpretation.

Phenotypic detection of resistance mechanisms

Phenotypic methods for detection of ESBL by the Modified double disk synergy test (MDDST)

A culture of each isolate was made on a 9 cm-diameter MHA plate, as recommended by CLSI $^{13}$. Discs with amoxacillin-clavulanic acid $(30 \mu \mathrm{g})$ and with cefotaxime $(30 \mu \mathrm{g})$, ceftazidime $(30 \mu \mathrm{g})$, aztreonam (30ug) and
ISSN 1110-5089

ISSN (on-line) 2356_9786

cefepime $(30 \mu \mathrm{g})$ were put at 16 to $20 \mathrm{~mm}$ distant from each other. Moreover, a piperacillin-tazobactam disc $(100 / 10 \mu \mathrm{g})$ was placed at a distance of 22 to $25 \mathrm{~mm}$ from the cefepime disc. The plates were overnight incubated at $37^{\circ} \mathrm{C}$ and ESBL production was considered positive when the zone of inhibition of the combination discs in comparison to the ceftazidime disc alone increased by $5 \mathrm{~mm}$ (Singh et al. 2014). Also, ESBL production is considered if the zone of inhibition produced by cefepime or any of the extended-spectrum cephalosporin discs showed a clear-cut increase towards the piperacillin-tazobactam (PIT) or amoxicillin-clavulanic acid discs (Shaikh $\boldsymbol{e t}$ al. 2016).

\section{Phenotypic detection of AmpC using AmpC Disk Test}

To screen for AmpC production among beta-lactam resistant isolates, the AmpC disc test was used. The standard strain E.coli ATCC 25922 was used for surface inoculation of MHA plate and a cefoxitin disc $(30 \mu \mathrm{g})$ was placed on the plate. Then AmpC disc (blank filter paper) was moistened with $20 \mu \mathrm{l}$ of sterile saline and inoculated with colonies of the test organism. The AmpC disc was placed touching the cefoxitin disc with the inoculated side facing downward. The plate was incubated at $35^{\circ} \mathrm{C}$ for $24 \mathrm{~h}$ and the presence of an indentation or flattening of cefoxitin inhibition zone indicated positive AmpC production (Kaur et al. 2019).

ESBL and AmpC Detection Discs set (MASTDISCS ID ${ }^{\mathrm{TM}}$ )

The co-production of ESBL and AmpC was investigated by using ESBL and AmpC Detection Discs set method (Nourrisson et al. 2015). The test is based on a combination disc method; Disk A contains cefpodoxime $(10 \mu \mathrm{g})$ as a screening agent, disk $B$ contains cefpodoxime $(10 \mu \mathrm{g})$ and clavulanate as ESBL inhibitor, disk $\mathrm{C}$ contains cefpodoxime $(10 \mu \mathrm{g})$ and cloxacillin as AmpC inhibitor, and disk D 
contains cefpodoxime $(10 \mu \mathrm{g})$ in combination with both clavulanate and cloxacillin as both ESBL and AmpC inhibitors.

Following the manufacturer's instructions, Mueller Hinton agar plates were surface inoculated by a sterile swab, each with a bacterial suspension of each isolate that is equivalent in density to a 0.5 McFarland standard. After placing of the disks on plates and incubation of the plates at $37{ }^{\circ} \mathrm{C}$ for $24 \mathrm{~h}$, the results were interpreted by comparing A, B, $\mathrm{C}$, and $\mathrm{D}$ inhibition zone diameters around the disks. If the differences $(\mathrm{B}-\mathrm{A}) \&(\mathrm{D}-\mathrm{C})$ was $\geq 5 \mathrm{~mm}$ and the differences (D-B) \& $(\mathrm{C}-\mathrm{A})$ was $<5 \mathrm{~mm}$, the organism was considered as a producer of ESBL alone, if (B-A) \& (D-C) were $<5 \mathrm{~mm}$ and $(\mathrm{D}-\mathrm{B}) \&(\mathrm{C}-\mathrm{A})$ were $\geq 5 \mathrm{~mm}$, the organism was a producer of $\mathrm{AmpC}$ alone, if (D-C) was $\geq 5 \mathrm{~mm}$ but (B-A) was $<5 \mathrm{~mm}$, the organism was considered to show ESBL and AmpC combined activity and if all zones were within $2 \mathrm{~mm}$ of each other, the organism was neither ESBL nor AmpC producer.

Phenotypic detection of M $\mathrm{KL}$ activity by imipenem-Ethylene diamine tetra acetic acid combined disc test (IMP-EDTA CDT)

To detect the production of metallo- $\beta$ lactamases (MBLs), the imipenem-EDTA combined disc test (IMP-EDTA CDT) was used that is based on the augmentation of imipenem inhibition zone by EDTA $(\mathrm{pH}=8.0)$ (Nagdeo et al. 2012).

Each tested isolate was grown to a turbidity equivalent to 0.5 McFarland standard and surface inoculated on MHA plate, then two imipenem discs $(10 \mu \mathrm{g})$ were placed on the agar surface. Ten $\mu \mathrm{L}$ of sterile $0.5 \mathrm{M}$ EDTA solution $(\mathrm{pH}=8)$ were added to one of disc pairs to have a final concentration of $750 \mu \mathrm{g}$. The inhibition zones of the imipenem and their counterpart EDTA-impregnated discs produced after incubation for $24 \mathrm{~h}$ at $37^{\circ} \mathrm{C}$ were compared. If the difference in the zone diameter differed by $\geq 7 \mathrm{~mm}$, MBLs production was considered positive (Nagdeo et al. 2012).

\section{Results}

\section{Isolation, identification of Enterobacteriaceae}

The identity of Enterobacteriaceae isolates was investigated biochemically as in table (1). Only 83 Enterobacteriaceae strains were recovered from the 160 samples $(51.88 \%)$ as in table (2). The most common bacteria isolated were $E$. coli (56.63\%), $K$. pneumoniae (38.55\%), Citrobacter spp. (2.41\%) and Proteus mirabilis (2.41\%).

Urine specimens gave the highest frequency of Enterobacteriaceae (59.02\%), followed by endotracheal tube (15.66\%), wound swab (13.3\%). Pus swab and sputum gave the lowest percentage of isolates; $(7.22 \%)$ and $(4.8 \%)$, respectively.

\section{Antimicrobial susceptibility}

High resistance was found with sulfamethoxazole/trimethoprim (69.88\%), intermediate resistance was exhibited by minocycline $(36.14 \%)$, while low resistance was reported with imipenem (10.84\%). Tigecycline was effective against all tested isolates (table 3).

\section{Phenotypic detection of resistance mechanisms}

MDR isolates are the isolates that show resistance to at least three different antibiotic classes. MDR isolates (49 isolates) were selected for screening of resistance mechanisms such as ESBL, AmpC, MBL and ESBL \& AmpC $\beta$-lactamase enzyme co-producers as shown in table 4 .

By screening of ESBL production by Modified Double Disc Test (MDDST), thirty four resistant isolates were ESBL producers (figure1). The IMPEDTA-CDT was performed for the nine imipenem resistant isolates and the results revealed that five of these isolates were $\mathrm{M} \beta \mathrm{L}$ producer (figure 2). Six isolates were AmpC $\beta$-lactamase producers (figure 3). On the other hand, four isolates were AmpC and ESBL co-producers (figure 4). 
Table 1: Biochemical characteristics of clinical Enterobacteriaceae isolates

\begin{tabular}{|c|c|c|c|c|c|}
\hline \multicolumn{2}{|c|}{ Biochemical reactions } & $\begin{array}{c}\text { E.coli } \\
\text { isolates }\end{array}$ & $\begin{array}{c}\text { K.pneumonia } \\
\text { isolates }\end{array}$ & $\begin{array}{c}\text { Citrobacter } \\
\text { isolates }\end{array}$ & P.mirabilis isolates \\
\hline \multicolumn{2}{|l|}{ Oxidase test } & & - & - & - \\
\hline \multicolumn{2}{|c|}{ Citrate utilization test } & _- & + & + & + \\
\hline \multicolumn{2}{|c|}{ Indole test } & + & $\ldots$ & _ & _ \\
\hline \multicolumn{2}{|l|}{ Urease test } & & + & & + \\
\hline \multicolumn{2}{|l|}{ Motility } & Motile & Non Motile & Motile & Motile Swarming \\
\hline \multirow{3}{*}{$\begin{array}{l}\text { Growth on } \\
\text { Triple sugar } \\
\text { iron agar }\end{array}$} & Slant & \multicolumn{3}{|c|}{ Acidic (yellow) } & Alkaline (red) \\
\hline & Butt & \multicolumn{3}{|c|}{ Acidic (yellow) } & Acidic (yellow) \\
\hline & $\mathrm{H}_{2} \mathrm{~S}$ & & & + & + \\
\hline \multicolumn{2}{|c|}{$\begin{array}{ll}\text { Morphology } & \text { on } \\
\text { Macconkey agar } & \end{array}$} & $\begin{array}{l}\text { Pink olonies } \\
\text { (Lactose } \\
\text { Fermenter) }\end{array}$ & $\begin{array}{c}\text { Mucoid pink } \\
\text { colonies (Lactose } \\
\text { Fermenter) }\end{array}$ & $\begin{array}{l}\text { Pink colonies } \\
\text { (Lactose } \\
\text { Fermenter) }\end{array}$ & $\begin{array}{l}\text { Colourless colonies (Non- } \\
\text { Lactose Fermenter) }\end{array}$ \\
\hline
\end{tabular}

Table 2: Distribution of different species of Enterobacteriaceae among collected specimens:

\begin{tabular}{|l|c|c|c|c|c|}
\hline \multirow{2}{*}{\multicolumn{1}{c|}{ Specimen }} & \multicolumn{4}{|c|}{ Micro - organisms } & \multirow{2}{*}{ Total } \\
\cline { 2 - 5 } & E.coli & K.pneumoniae & Citro. spp & P.mirabilis & \\
\hline Endotracheal tube & $7(53.8 \%)$ & $6(46.2 \%)$ & 0 & 0 & $13(15.66 \%)$ \\
\hline Pus swab & $2(33.3 \%)$ & $3(50 \%)$ & $1(16.7 \%)$ & 0 & $6(7.22 \%)$ \\
\hline Urine & $31(63.3 \%)$ & $16(32.7 \%)$ & 0 & $2(4.1 \%)$ & $49(59.02 \%)$ \\
\hline Sputum & $2(50 \%)$ & $2(50 \%)$ & 0 & 0 & $4(4.8)$ \\
\hline Wound swab & $5(45.5 \%)$ & $5(45.5 \%)$ & $1(9.1 \%)$ & 0 & $11(13.3 \%)$ \\
\hline Total & $47(56.6 \%)$ & $32(38.6 \%)$ & $2(2.4 \%)$ & $2(2.4 \%)$ & $83(100 \%)$ \\
\hline \multicolumn{7}{|c|}{$\chi 2=12.44, \mathrm{P}=0.41$} \\
\hline
\end{tabular}

Table 3: Antibiotic susceptibility of tested Enterobacteriaceae isolates

\begin{tabular}{|l|c|c|c|c|c|}
\hline \multirow{2}{*}{ Antibiotics } & \multicolumn{3}{|c|}{ Number (\%) of resistant isolates } & \multirow{2}{*}{ Total } \\
\cline { 2 - 5 } & E-coli n=47 & K.pneumonian=32 & Citro.n=2 & P.mirabilisn=2 & \\
\hline Amoxicillin/Clavulanic & $7(63.6)$ & $4(36.4)$ & 0 & 0 & 11 \\
\hline Ampicillin/Sulbactam & $14(43.75)$ & $15(46.88)$ & $2(6.25)$ & $1(3.12)$ & 32 \\
\hline Cefotaxime & $23(53.49)$ & $16(37.21)$ & $2(4.65)$ & $2(4.65)$ & 43 \\
\hline Cefotriaxone & $23(54.76)$ & $17(40.48)$ & $1(2.38)$ & $1(2.38)$ & 42 \\
\hline Ceftazidime & $24(54.54)$ & $17(38.64)$ & $2(4.55)$ & $1(2.27)$ & 44 \\
\hline Cefepime & $21(55.3)$ & $16(42.1)$ & $1(2.6)$ & 0 & 38 \\
\hline Cefoxitin & $9(56.25)$ & $6(37.5)$ & $1(6.25)$ & 0 & 16 \\
\hline Imipenem & $4(44.4)$ & $5(55.6)$ & 0 & 0 & 9 \\
\hline Tetracycline & $28(54.9)$ & $19(37.3)$ & $2(3.9)$ & $2(3.9)$ & 51 \\
\hline Minocycline & $17(56.67)$ & $12(40)$ & $1(3.33)$ & 0 & 30 \\
\hline Tigecycline & 0 & 0 & 0 & 0 & 0 \\
\hline Amikacin & $13(54.2)$ & $11(45.8)$ & 0 & 0 & 24 \\
\hline Gentamicin & $15(57.7)$ & $11(42.3)$ & 0 & 0 & 26 \\
\hline Ciprofloxacin & $30(57.7)$ & $18(34.6)$ & $2(3.85)$ & $2(3.85)$ & 52 \\
\hline $\begin{array}{l}\text { Sulfamethoxazole/ } \\
\text { Trimethoprim }\end{array}$ & $39(67.24)$ & $15(25.86)$ & $2(3.45)$ & $2(3.45)$ & 58 \\
\hline Aztreonam & $25(56.82)$ & $18(40.91)$ & $1(2.27)$ & 0 & 44 \\
\hline
\end{tabular}


Table 4: Resistance mechanisms detected among different species of isolated Enterobacteriacaeae

\begin{tabular}{|c|c|c|c|c|c|c|}
\hline & & ESBL only & AMPC only & ESBL / AMPC Co-producer & MBL & Total \\
\hline \multirow{2}{*}{$E$-coli } & No. & 19 & 4 & 2 & 2 & 27 \\
\hline & $\%$ & 38.8 & 8.2 & 4.1 & 4.1 & 55.1 \\
\hline \multirow{2}{*}{$\begin{array}{c}\text { Klebsiella } \\
\text { pneumonia }\end{array}$} & No. & 15 & 2 & 1 & 3 & 21 \\
\hline & $\%$ & 30.6 & 4.1 & 2 & 6.1 & 42.9 \\
\hline \multirow{2}{*}{$\begin{array}{c}\text { Citrobacter } \\
\text { spp }\end{array}$} & No. & 0 & 0 & 1 & 0 & 1 \\
\hline & $\%$ & 0 & 0 & 2 & 0 & 2 \\
\hline \multirow{2}{*}{$\begin{array}{c}\text { Proteus } \\
\text { mirabilis } \\
\end{array}$} & No. & 0 & 0 & 0 & 0 & 0 \\
\hline & $\%$ & 0 & 0 & 0 & 0 & 100 \\
\hline \multirow{2}{*}{ Total } & No. & 34 & 6 & 4 & 5 & 49 \\
\hline & $\%$ & 69.4 & 12.2 & 8.2 & 10.2 & 100 \\
\hline
\end{tabular}

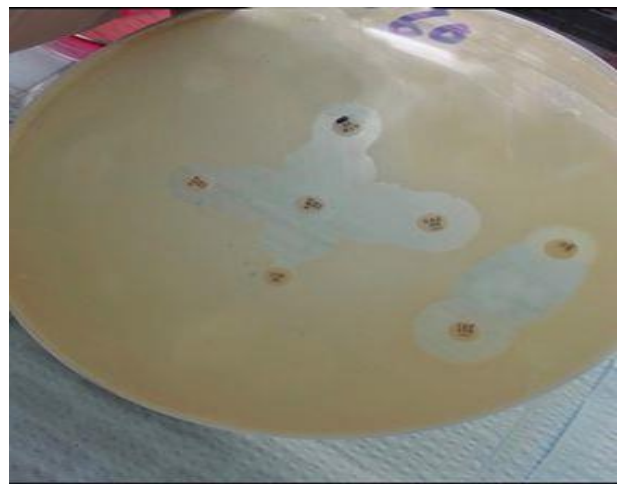

Figure 1: Detection of ESBL by modified double disk synergy test (MDDST), showing a clear-cut increase towards the piperacillin-tazobactam (PIT) disc or amoxacillin-clavulinic acid disc that considered ESBL producer.

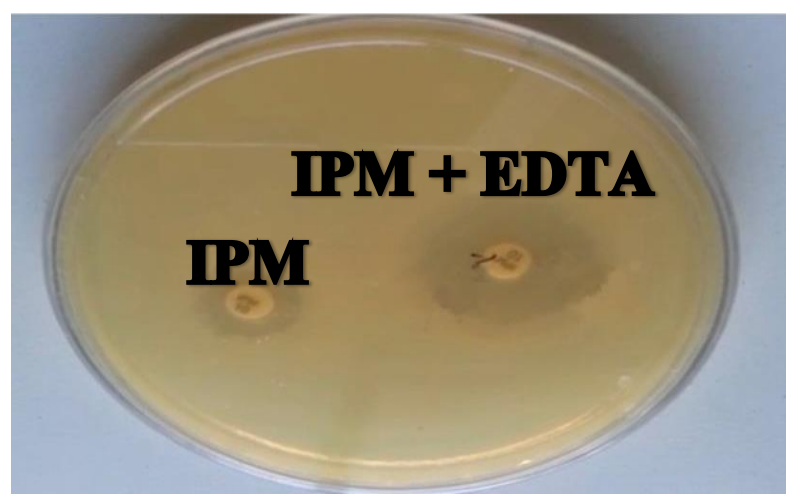

Figure 2: Detection of MBL by IMP-EDTA-CDT method, positive result when the increase in zone of inhibition of imipenem disc in presence of EDTA is $\geq 7 \mathrm{~mm}$ than imipenem disc alone.

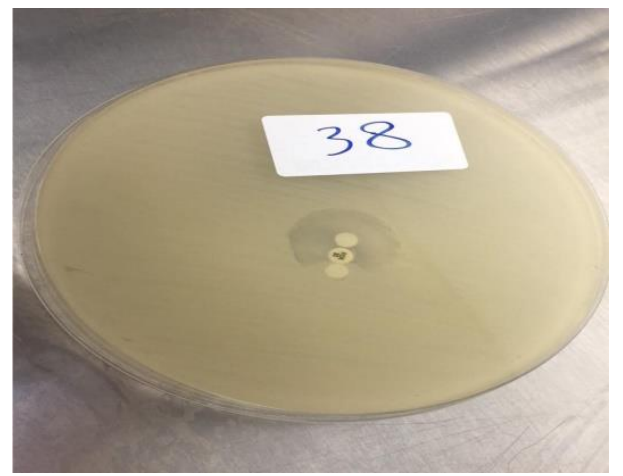

Figure 3: Detection of AmpC by AmpC disc test, positive isolates showed an indentation or flattening of cefoxitin inhibition zone.

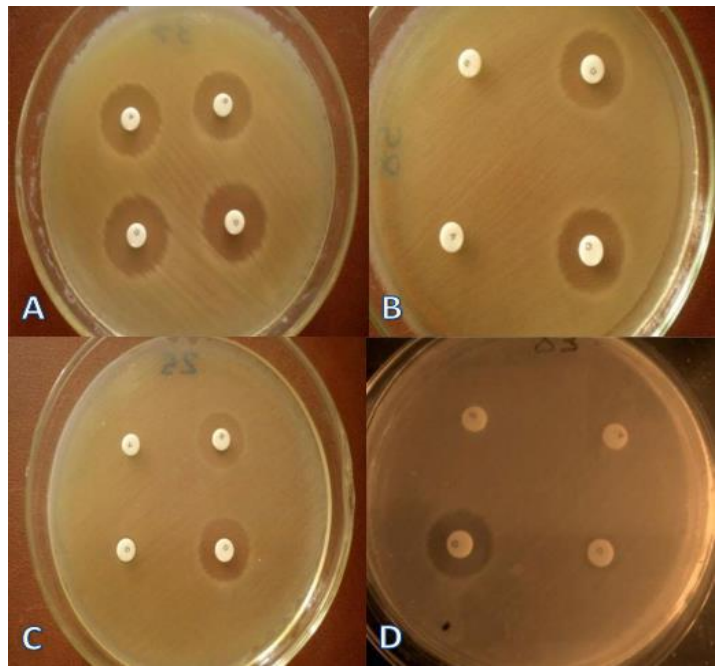

Figure 4: Phenotypic detection by ESBL and AmpC detection set.

A) Sensitive non ESBL non AmpC strain, B) AmpC positive strain, C) ESBL positive strain, D) Combined ESBL and AmpC. 
Zagazig J. Pharm. Sci. June, 2020

Vol. 29, Issue 1, pp. 9-20

\section{Discussion}

The Enterobacteriaceae family is a heterogeneous group of naturally found Gramnegative bacteria in the intestinal tracts of humans and animals. They are frequently encountered among the nosocomial pathogens with the urinary tract infections (UTIs) as the most common, while infections of the bloodstream and lower respiratory tract are the most dangerous as life threatening (RamosVivas et al. 2019).

The Excessive drug prescription and inappropriate use of antibiotics represent the most important threats that affect public health worldwide, resulting in the emergence of multidrug resistance. It is thus vital to understand the antimicrobial resistance mechanisms of these bacteria in order to develop new therapeutic tools to combat the public health problems related to infections such as the development of new antibiotics (Santajit and Indrawattana 2016).

The present study showed that Enterobacteriaceae especially Escherichia coli and Klebsiella species were the most common organisms isolated. These results agreed with Shakya et al. (2017), who found that the predominant pathogens isolated from patients infected with UTIs were E.coli and Klebsiella pneumoniae.

In our study Proteus spp. and Citrobacter species showed a much lower prevalence; they represented $2.41 \%$ of isolated bacteria each. These results were lower than those reported by Chen et al. (2012) (8.9\% for Proteus spp.) and Yesuf et al. (2016) (8\% for Citrobacter species).

On regarding the type of isolated bacteria as correlated to the type of the sample collected, the present study showed that E.coli was isolated mainly from urine followed by endotracheal tub, sputum, wound swab, and finally pus swab. Our results were somewhat different than those reported by Taj et al.
ISSN 1110-5089

ISSN (on-line) 2356_9786

(2018) who found that urine was the most common source for bacteria, but it was followed by pus, endotracheal tube, sputum and finally swab samples.

The present study shows that among Enterobacteriaceae, the highest rate of resistance was found against sulfamethoxazoletrimethoprim $(69.88 \%)$ followed by ciprofloxacin $(62.65 \%)$. These results were different from other reports. Thus, Yekani et al. (2018) found a higher resistance rate of Enterobacteriaceae isolates to sulfamethoxazole-trimethoprim $(96.8 \%)$, while a lower one (44.1\%) was found by Wu $\boldsymbol{e t}$ al. (2016).

Our study showed that the resistance rates for the cephalosporins cefotaxime, ceftazidime and ceftriaxone ranged between $50.6 \%$ and $53.02 \%$. These results were in accordance with the study of Adhikari et al. (2018) who found resistance percentages between $51 \%$ and $54 \%$ to the same cephalosporins. On the other hand, the lowest rate resistance was to imipenem. Alipourfard and Nili (2010) reported complete sensitivity to imipenem in their study.

The difference in the rate of isolated bacteria among different studies may be attributed to the difference in location, types of studied specimens, predisposing factors and number of studied cases (Eshetie et al. 2015).

Then the rate of MDR isolates was detected among the tested bacteria. About $59 \%$ of the isolates were MDR. Odonkor and Addo (2018) found that MDR E. coli isolates represent $49.48 \%$ of the tested isolates. MDR isolates were used for the screening of the production of ESBL, AmpC, ESBL\& AmpC co-producers and MBL enzymes.

This study revealed that the frequency of ESBL producers constituted $69.4 \%$ of the tested isolates; a result similar to that reported by Shrestha et al. (2016) who found that $64.9 \%$ of isolates obtained from community acquired urinary tract infection were able to 
produce ESBL. Our study revealed that $38.8 \%$ of E. coli, and $30.6 \%$ of Klebsiella spp. were ESBL producers, while none of the isolated Proteus strains were ESBL producers. A Nigerian study of Horsefall et al. (2017) revealed more or less similar results, while Quan et al. (2017) found different results (ESBL producers were $55.5 \%$ among E.coli isolates and $16.5 \%$ among $K$. pneumoniae isolates).

AmpC producing isolates in our study represented $12.2 \%$ of tested isolates; a result that lower than that reported by Shinu et al. (2014) $(21.76 \%)$ in India, but comparable to another study Ibadin et al. (2017) that found a rate of $15.2 \%$ for AmpC production. The coproduction of ESBL and AmpC was reported in $8.2 \%$ of isolates in this study. However, Shayan and Bokaeian (2015) found lower prevalence of combined ESBL and AmpC production $(5 \%)$.

Considering the production of MBL, $10.2 \%$ of imipenem resistant isolates were MBL producers. Fazeli et al. (2015) study in Isfahan showed a rate of $10.2 \%$ of MBL producers among carbapenem resistant $K$. pneumonia, while Ghotaslou et al. (2018) reported only a rate of $4.9 \%$ for carbapenemase production. Moreover, an Indian study Mwinga et al. (2018) mentioned a higher prevalence of MBL $(18.46 \%)$. This difference observed may be explained by the variation in the number of isolates studied and the difference in the methods used for detection in each study.

As a result of the high rate of MDR and resistance to beta-lactams in our study, we tested the activity of different members of tetracyclines to screen for the most effective one against tested isolates. The susceptibility to tetracycline, minocycline was $38.55 \%$ and $63.86 \%$. However, tigecycline was effective against all tested isolates that could produce ESBL and/or AmpC and carbapenemases. Devarajan et al. (2018) previously reported susceptibilities of $98.13 \%$ and $66.39 \%$ to tigecycline and minocycline, respectively against Gram-negative isolates. Moreover, previous work emphasizes our results. Thus, (Mariappan et al. 2011, Mustafa 2017, Sattar et al. 2016, Gandham and Amatullah 2015 and Vega and Dowzicky 2017) reported very high or complete sensitivity of ESBL producing isolates to tigecycline. Many other reports support our results. Shetty et al. (2016) revealed that tigecycline is highly active against MDR nosocomial Enterobacteriaceae. Also, Tigecycline showed potent activity against wide range of carbapenem-resistant Gramnegative clinical isolates Singh et al. (2017). Furthermore, (Oliveira et al. 2018, Pfaller et al. 2017 and Rajni et al. 2018) found very low or no resistance to tigecycline among carbapenem resistant Enterobacteriaceae (CRE).

\section{Conclusion}

High rate of antibiotic among Enterobacteriaceae was reported. Betalactamases; ESBLs, AmpC and MBL contributed to such resistance. Tigecycline may be an alternate to beta-lactams against MDR Enterobacteriaceae.

\section{Conflict of interest}

The authors declare that they have no conflict of interest.

\section{REFERENCES}

Adhikari RP, Shrestha S, Rai JR, Amatya R. (2018). Antimicrobial resistance patterns in clinical isolates of Enterobacteriaceae. Nepalese Medical Journal 1:74-78.

Alipourfard I, Nili NY. (2010). Antibiogram of extended spectrum beta-lactamase (ESBL) producing Escherichia coli and Klebsiella pneumoniae isolated from hospital samples. Bangladesh Journal of Medical Microbiology 4(1):32-36.

Atlas RM, Parks LC. (2004). Handbook of Microbiological Media. 4th ed. CRC Press.

Bassetti M, Peghin M, Pecori D. (2016). The management of multidrug-resistant Enterobacteriaceae. Current Opinion in Infectious Disease 29(6):583-594. 
Zagazig J. Pharm. Sci. June, 2020

Vol. 29, Issue 1, pp. 9-20

Caron Y, Chheang R, Puthea N, Soda M, Boyer S, and Tarantola $A$ et al. (2018). Beta-lactam resistance among Enterobacteriaceae in Cambodia: The four-year itch. International Journal of Infectious Diseases 66:7479.

Cheesbrough M. (2006). District Laboratory Practice in Tropical Countries, 2nd ed. Cambridge University Press.

Chen C Y, Chen Y H, Lu P L, Lin W R, Chen T C, and Lin C Y. (2012). "Proteus mirabilis urinary tract infection and bacteremia: risk factors, clinical presentation, and outcomes." Journal of Microbiology, Immunology and Infection 45(3):228-236.

CLSI. (2017). Methods for dilution antimicrobial susceptibility tests for bacteria that grow aerobically, approved standard, 27th ed. CLSI supplements M100S26, volume 35 (2), Wayne, PA: Clinical and Laboratory Standards Institute.

CLSI. (2017). Performance Standards for Antimicrobial Susceptibility Testing, 27th ed. CLSI supplements M100S. Wayne, PA: Clinical and Laboratory Standards Institute.

Devarajan V, Bansal N, Ghafur KA. (2018). Comparative analysis of tigecycline and minocycline susceptibility among Gram-negative isolates. Journal of Contemporary Clinical Practice 4(1):8-12.

Eshetie S, Unakal C, Gelaw A, Ayelign B, Endris M, and Moges F. (2015). Multidrug resistant and carbapenemase producing Enterobacteriaceae among patients with urinary tract infection at referral hospital, northwest Ethiopia. Antimicrobial Resistance and Infection Control 4:12.

EUCAST. European Committee on Antimicrobial Susceptibility Testing. (2016). Breakpoint tables for interpretation of MICs and zone diameters.

Fair RJ, Tor Y. (2014). Antibiotics and bacterial resistance in the 21 st century. Perspectives in medicinal chemistry 6:25-64.

Fazeli H, Norouzi-Barough M, Ahadi AM, Shokri D, and Solgi H. (2015). Detection of New Delhi metallobeta-lactamase-1 (NDM-1) in carbapenem-resistant Klebsiella pneumoniae isolated from a university hospital in Iran. Hippokratia 19(3):205-209.

Gandham P, Amatullah F. (2015). Antibiotic susceptibility and resistance patterns of Enterobacteriaceae in a teaching hospital in a rural area. Journal of Microbiology and Biotechnology Research 5(2):1-4.

Ghotaslou R, Sadeghi MR, Akhi MT, Hasani A, and Asgharzadeh M. (2018). Prevalence and antimicrobial susceptibility patterns of ESBL, AmpC and Carbapenemase-producing Enterobactericeae isolated
ISSN 1110-5089

ISSN (on-line) 2356_9786

from hospitalized patients in Azerbaijan, Iran. Iranian Journal of Pharmaceutical Research 17(Suppl):79-88.

Horsefall SJ, Abbey SD, Nwokah E, and Okonko I. (2017). Prevalence of extended-spectrum betalactamases (ESBLs) and plasmid status of Eschericha coli and Klebsiella pneumoniae isolates from clinical sources in UPTH, Port-Harcourt, Nigeria. New York Science Journal 10(3):29-39.

Ibadin EE, Omoregie R, Igbarumah IO, and Anogie NA. (2017). Prevalence of extended spectrum $\beta$ lactamase, AmpC $\beta$-lactamase and Metallo- $\beta$-lactamase among Gram negative bacilli recovered from clinical specimens in Benin city, Nigeria. International Journal of Enteric Pathogens 5(3):85-91.

Iredell J, Brown J, Tagg K. (2016). Antibiotic resistance in Enterobacteriaceae: Mechanisms and clinical implications. British medical journal 352:h6420. Kaur S, Gupta V, Chhina D. (2019). AmpC $\beta$ lactamases producing Gram-negative clinical isolates from a tertiary care hospital. Journal of Mahatma Gandhi Institute of Medical Sciences 21(2):107-110.

Mandell G, Bennett J, Dolin R. (2009) Mandell, Douglas, and Bennett's Principles and Practice of Infectious Diseases. 7th ed. Churchill Livingstone/Elsevier.

Mariappan S, Sekar U. (2011). In-vitro activity of tigecycline against Gram positive and Gram negative isolates in a tertiary care hospital. Journal of Clinical and Diagnostic Research 5(8):1559-1563.

Mustafa SA. (2017). High Prevalence and Antibiogram Pattern of extended spectrum beta lactamases producing Escherichia coli and Klebsiella pneumonia isolated from inpatients units in a general hospital in Saudi Arabia. EC microbiology 5(1):30-35.

Mwinga MM, Mahale RP, Sumana MN.(2018). Phenotypic detection of AMPC $\beta$-lactamase and metallo- $\beta$-lactamase production among uropathogenic E.coli. International Journal of Scientific Research 7(6):68-71.

Nagdeo NV, Kaore NM, Thombare VR. (2012) Phenotypic methods for detection of various $\beta$ lactamases in Gram-negative clinical isolates: Need of the hour. Chronicles of Young Scientists 3(4):292-298.

Nourrisson C, Tan RN, Hennequin C, Gibold L, Bonnet R, and Robin F. (2015). The MAST ${ }^{\circledR}$ D68C test: an interesting tool for detecting extended-spectrum $\beta$-lactamase (ESBL)-producing Enterobacteriaceae. European Journal of Clinical Microbiology \& Infectious Diseases 34(5):975-983.

Odonkor ST, Addo KK. (2018). Prevalence of multidrug-resistant Escherichia coli isolated from drinking water sources. International Journal of Microbiology 7204013. 
Zagazig J. Pharm. Sci. June, 2020

Vol. 29, Issue 1, pp. 9-20

Oliveira CF de, Ferrugem F, Schmidt RV, Pra D, and Horta JA. (2018). Activity of carbapenems and tigecycline against ESBL producing Escherichia coli and Klebsiella spp. Jornal Brasileiro de Patologia e Medicina Laboratorial 54(1):34-36.

Partridge SR. (2015). Resistance mechanisms in Enterobacteriaceae. Pathology 47(3):276-284.

Paterson DL. (2006). Resistance in Gram-negative bacteria: Enterobacteriaceae. American Journal of medicine 119(6): S20-S28.

Pfaller MA, Flamm RK, Duncan LR, Mendes RE, Jones RN, and Sader HS. (2017). Antimicrobial activity of tigecycline and cefoperazone/sulbactam tested against 18,386 Gram-negative organisms from Europe and the Asia-Pacific region (2013-2014). Diagnostic Microbiology and Infectious Disease 88(2):177-183.

Quan J, Zhao D, Liu L, Chen Y, Zhou J, Jiang Y et al. (2017). High prevalence of ESBL-producing Escherichia coli and Klebsiella pneumoniae in community-onset bloodstream infections in China. Journal of Antimicrobial Chemotherapy 72(1):273-280. Rajni E, Rajpurohit V, Rathore P, and Khathri PK. (2018). Epidemiology of carbapenem-resistant Enterobacteriaceae colonization in ICU: a pilot study from a tertiary care hospital in Western Rajasthan, India. International Journal of Research in Medical Sciences 6(10):3340-3345.

Ramos-Vivas J, Chapartegui-González I, FernándezMartínez M, Gonzaiez-Rico C, Fortun J, and Escudero $R$ et al. (2019). Biofilm formation by multidrug resistant Enterobacteriaceae strains isolated from solid organ transplant recipients. Scientific Reports 9:8928.

Santajit S and Indrawattana N. (2016). Mechanisms of antimicrobial resistance in ESKAPE pathogens. BioMed Research International 2475067.

Sattar A, Khokhar AR, Abbasi SA, Kaleem F, Faraz A, and Faqir F. (2016). In vitro activity of tigecycline against multi drug resistant bacteria. Annals of Pakistan Institute of Medical Sciences 12(1):31-35.

Shaikh NK, Mundhada SG, Lalngaihzuali R, and Ingole KV. (2016). Comparison of different phenotypic methods for the detection of extended spectrum blactamase (ESBL) in bacterial isolates from tertiary care centre. International Journal of Current Research and Review 8(11):10-14.

Shakya P, Shrestha D, Maharjan E, Sharma VK, and Paudyal R. (2017). ESBL production among E.coli and Klebsiella spp. causing urinary tract infection: A hospital based study. The open Microbiology Journal 11:23-30.
ISSN 1110-5089

ISSN (on-line) 2356_9786

Shayan S, Bokaeian M. (2015). Detection of ESBLand AmpC-producing E.coli isolates from urinary tract infections. Advanced Biomedical Research 4:220.

Shetty SNS, Sumangala B, Samaga MP, and Sangannavar AB. (2016). Antibiotic effect of tigecycline on Gram negative bacilli. Indian Journal of Microbiology Research 3(3):305-307.

Shinu P, Bareja R, Goyal M, Singh VA, Mehrishi P, and Bansal $M$ et al. (2014). Extended-spectrum $\beta$ lactamase and AmpC $\beta$-lactamase production among Gram-negative bacilli isolates obtained from urinary tract infections and wound infections. Indian Journal of Clinical Practice 24(11):1019-1026.

Shrestha A, Manandhar S, Pokhrel P, Panthi P, and Chaudhary D. (2016). Prevalence of extended spectrum beta-lactamase (ESBL) producing multidrug resistance Gram-negative isolates causing urinary tract infection. EC Microbiology 4:749-755.

Singh RM, Chongtham U, Huidrom, and Singh HL. (2017). Evaluation of in vitro activity of tigecycline against carbapenemase-producing Gram-negative clinical isolates. Annals of Tropical Medicine and Public Health 10(3):641-645.

Singh RM, Singh HL. (2014). Comparative evaluation of six phenotypic methods for detecting extendedspectrum beta-lactamase-producing Enterobacteriaceae. Journal of Infection in Developing Countries 8(4):408415.

Song Y, Hu L, Shu Q, Ye J, Liang J, and Chen X et al. (2018). Tigecycline salvage therapy for critically ill children with multidrug-resistant/extensively drugresistant infections after surgery. International Journal of Infectious Diseases 75:82-88.

Taj A, Shamim A, Khanday SB, Ommid M. (2018). Prevalence of common nosocomial organisms in surgical intensive care unit in North India: A hospital-based study. International Journal of Critical Illness and Injury Science 8(2):78-82.

Thenmozhi S, Moorthy K, Sureshkumar BT, and Suresh M. (2014). Antibiotic resistance mechanism of ESBL producing Enterobacteriaceae in clinical field: A review. International Journal of Pure \& Applied Bioscience 2 (3):207-226.

Vega S, Dowzicky MJ. (2017). Antimicrobial susceptibility among Gram-positive and Gram-negative organisms collected from the Latin American region between 2004 and 2015 as part of the tigecycline evaluation and surveillance trial. Annals of Clinical Microbiology and Antimicrobials 16(1):50.

Wu CT, Lee HY, Chen CL, Tuan PL, and Chiu CH. (2016). High prevalence and antimicrobial resistance of urinary tract infection isolates in febrile young children without localizing signs in Taiwan. Journal of 
Zagazig J. Pharm. Sci. June, 2020

Vol. 29, Issue 1, pp. 9-20

Microbiology. Immunology and Infection 49(2):243248.

Yekani M, Baghi HB, Sefidan FY, Azargun R, Memar MY, and Ghotaslou R. (2018). The rates of quinolone, trimethoprim/sulfamethoxazole and aminoglycoside resistance among Enterobacteriaceae isolated from urinary tract infections in Azerbaijan, Iran. GMS Hygiene and Infection Control 13: Doc07.
ISSN 1110-5089

ISSN (on-line) 2356_9786

Yesuf A, Wondimeneh Y, Gebrecherkos T, and Moges F. (2016). Occurrence of potential bacterial pathogens and their antimicrobial susceptibility patterns isolated from herbal medicinal products sold in different markets of Gondar Town, northwest Ethiopia. International Journal of Bacteriology 1959418.

\section{فعالية مضاد تايجيسيكلين في المختبر ضد عزلات إكلينيكية محلية من عائلة إنترويكترياسي

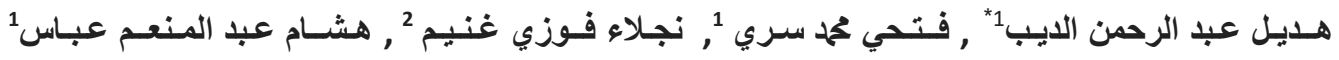

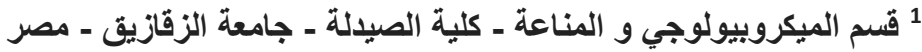

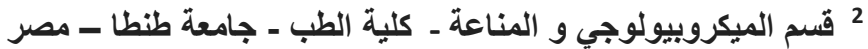

البكتبريا المعوية (الانتيروباكترياسي) تعتبر سببا هاما لكثير من أنواع العدوى المنتشرةعلى نطاق واسع مثنل التهابات

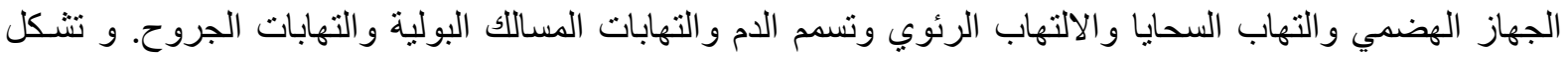

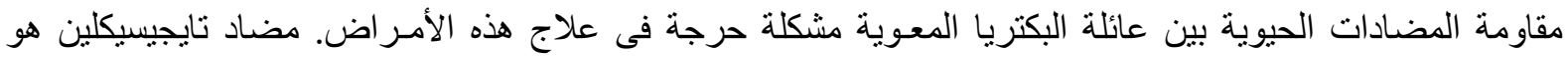

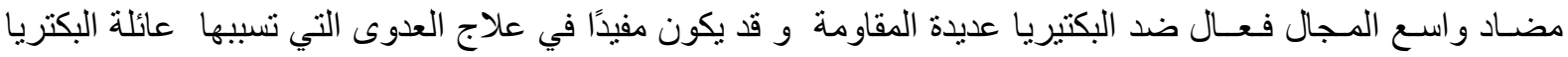
المعوية. تهدف هذه الدراسة الى تقدير فعالية مضاد تايجيسيكلين في المختبر ضد عزلات لات إكلينيكية محلية من عائلة إنتروبكترياسي

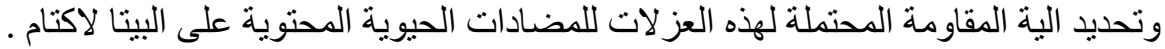

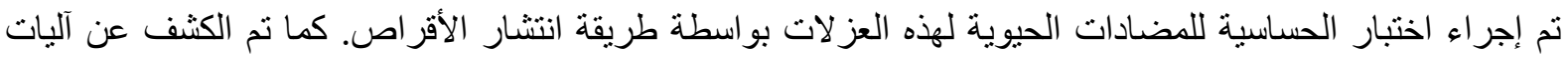

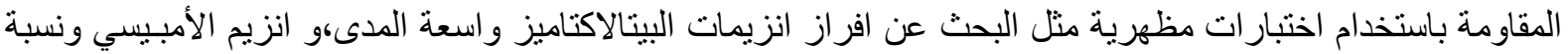
تو اجدهما معاو ايضا انزيم الميتالوبينالاكتاميز.

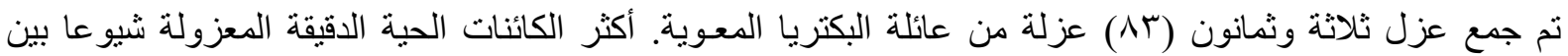

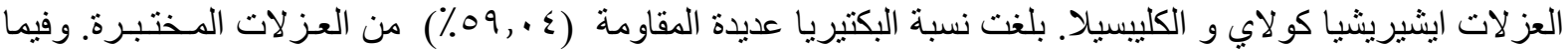

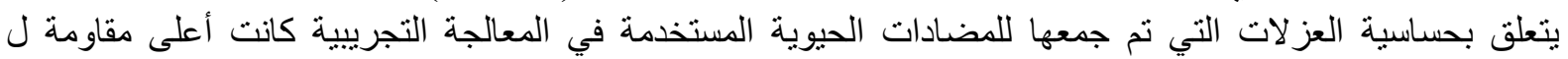

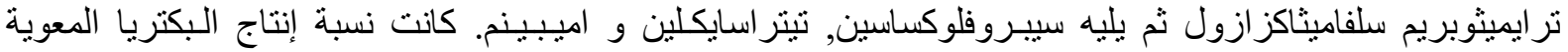

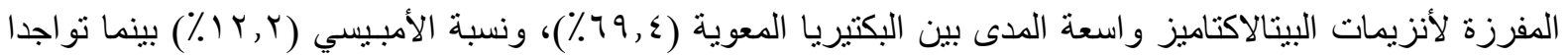

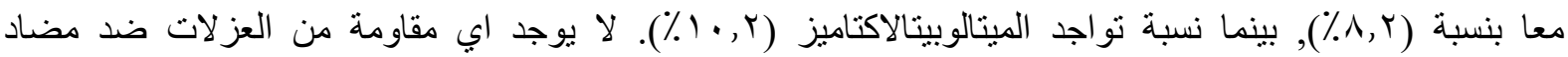
هذه الدراسة اوضحت النشاط القوى والفعـال لمضاد تايجيسيكلين ضد عزلات لات عائلة البكتريا المعوية

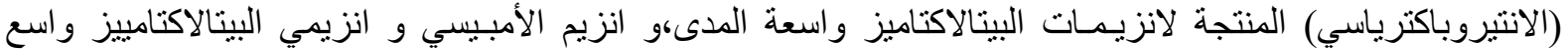

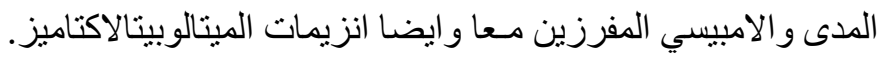

